\title{
Insulin- and glucagon-like peptide-1-induced changes in heart rate and vagosympathetic activity: why they matter
}

\author{
P. Valensi • S. Chiheb $・$ M. Fysekidis
}

Received: 6 February 2013 / Accepted: 7 March 2013 /Published online: 13 April 2013

(C) Springer-Verlag Berlin Heidelberg 2013

\begin{abstract}
Heart rate (HR) predicts cardiovascular morbidity and mortality in individuals either with or without diabetes. In type 2 diabetic patients, cardiac autonomic neuropathy is a risk marker for cardiac morbidity and mortality. A major pathogenic potential may be attributed to vagal depression and sympathetic predominance. In this issue of Diabetologia, Berkelaar et al (DOI: 10.1007/s00125-013-2848-6) examined the effects of euglycaemic, and hyperglycaemic clamp with the addition of glucagon-like-peptide-1 (GLP-1) and arginine, on cardiac vagal control in a large number of healthy subjects. After adjustments for age, BMI and insulin sensitivity, insulin associations with HR remained partially intact while those with vagal control disappeared. This suggested that BMI and insulin sensitivity, but not insulin levels, were the main drivers of cardiac vagal control. GLP-1 infusion during hyperglycaemia increased $\mathrm{HR}$ and $\mathrm{BP}$ and produced a statistically non-significant decrease in measures of cardiac vagal control compared with values before any manipulation of insulin levels. This commentary summarises how, and to what extent, insulin and GLP-1 affect autonomic nervous system activity, HR and BP. More information is needed on the mechanisms through which acute administration of, and long-term treatment with, GLP-1 may affect haemodynamics and autonomic activity in diabetic and obese patients, since this may influence cardiovascular outcomes.
\end{abstract}

Keywords Blood pressure - Cardiac autonomic neuropathy · GLP-1 $\cdot$ Heart rate $\cdot$ Insulin $\cdot$ Obesity $\cdot$ Type 2 diabetes

\footnotetext{
P. Valensi $(\bowtie) \cdot S$. Chiheb $\cdot$ M. Fysekidis

Department of Endocrinology-Diabetology-Nutrition, AP-HP, Jean Verdier Hospital, Paris-Nord University, CRNH-IdF, Avenue du 14 juillet,

93143 Bondy Cedex, France

e-mail: paul.valensi@jvr.aphp.fr
}

\author{
Abbreviations \\ CAN Cardiac autonomic neuropathy \\ GLP-1 Glucagon-like peptide-1 \\ HR Heart rate \\ LF/HF Ratio of low frequency peak/high frequency peak \\ MSNA Muscle sympathetic nerve activity
}

\section{Introduction}

An elevated heart rate (HR) is a predictor of cardiovascular morbidity and mortality in individuals with and without diabetes [1-3]. A high HR may result from several factors, including reduced vagal activity or high sympathetic activity. HR variability as assessed by cardiovascular autonomic reflex tests, which largely reflect cardiac vagal control, is lower in diabetic patients and has been recognised as an early marker of cardiac autonomic neuropathy (CAN). Lower HR variability is often observed in patients with recently diagnosed type 2 diabetes, while sympathetic activity is depressed later and causes postural hypotension that is easy to detect [4]. The role of glycaemic control in CAN is supported by DCCT data showing that, in type 1 diabetes, intensive insulin treatment reduced the incidence of CAN by $53 \%$ compared with conventional therapy [5]. Similarly, the Steno 2 study showed that, in type 2 diabetic patients, an intensive multifactorial cardiovascular risk intervention reduced the progression or the development of CAN [6].

Reduced HR variability is common in non-diabetic obese patients [7] and in individuals with impaired glucose tolerance [8]. Overweight is a major determinant of HR variability in the general population [9] and is also a major contributor to CAN in patients with type 2 diabetes [10]. In addition, elevated sympathetic activity and diminished vagal activity have been observed in individuals with the metabolic syndrome [11]. Thus, a vagosympathetic imbalance may occur prior to diabetes 
as a result of overweight and insulin resistance. This is strongly supported by the recent demonstration that progression to type 2 diabetes is associated with increased central sympathetic drive, blunted sympathetic responsiveness and altered noradrenaline (norepinephrine) disposition [12]. In addition to obesity and diabetes, several factors associated with these conditions, such as insulin, proinsulin, C-peptide, glucose, leptin, adiponectin and NEFA, have been shown to affect the autonomic nervous system [13, 14].

In the Diabetes Prevention Program, randomisation of individuals considered to be at high risk of developing diabetes (BMI $24 \mathrm{~kg} / \mathrm{m}^{2}$, fasting glucose 5.3-6.9 $\mathrm{mmol} / \mathrm{l}$, and $2 \mathrm{~h}$ glucose $7.8-11.0 \mathrm{mmol} / \mathrm{l}$ ) to the lifestyle modification arm, which was aimed at weight reduction and engaging in physical activity, improved indices of autonomic function [15]. In overweight individuals, weight loss improved vagosympathetic balance, especially when restriction of energy intake was combined with exercise [16]. Regarding the influence of sympathetic activity in weight loss in obese individuals, higher resting sympathetic drive (as assessed by muscle sympathetic nerve activity [MSNA]) and sympathetic responsiveness to an oral glucose challenge were reported to predict dietary weight loss [17]. Similarly, among obese subjects who had undergone gastric bypass surgery, the greatest reductions in excess body weight were achieved by those observed to have a preserved capacity to shift their cardiac autonomic balance towards a sympathetic predominance during a euglycaemic-hyperinsulinaemic clamp [18].

\section{Pathogenic potential of a vagosympathetic imbalance}

Vagal depression and sympathetic predominance are likely to contribute to insulin resistance and a decline in insulin secretion. Moreover, higher HR predicted incident diabetes in the Diabetes Prevention Program [15]. In overweight patients, glucose oxidation rate is negatively correlated with serum insulin levels only in those with cardiac vagal impairment, suggesting that sympathetic overactivity may produce a more severe insulin resistance [19]. In addition, glucose utilisation is negatively correlated with the low frequency/high frequency (LF/HF) ratio on spectral analysis of HR variability, which means that glucose utilisation is reduced when sympathetic activity is predominant [20].

In type 2 diabetic patients, CAN is a risk marker for allcause and cardiac mortality [21], stroke, coronary events, silent myocardial ischaemia, left ventricular dysfunction, arrhythmia, and nephropathy progression [4]. Sympathetic predominance may account for these disorders and may be involved in the increased risk of cardiovascular events. Regarding the role of vagosympathetic imbalance in hypertension, some data in rats suggest that high vagal activity may protect against obesity-associated hypertension [22].
Other experimental data indicate a link between arterial stiffness and activation of the autonomic nervous system [23]. Both in patients with type 1 and type 2 diabetes, we reported that the prevalence of hypertension increases with CAN severity, which indicates a defect in vagal activity and a relative sympathetic override in hypertension [24]. In line with this, sympathetic activity is greater and baroreflex sensitivity more severely impaired in individuals with obesity and hypertension than in those with either obesity or hypertension alone [25], and similar findings have been observed for individuals with the metabolic syndrome and hypertension [26].

\section{Effects of insulin on vagosympathetic activity}

Insulin and glucagon-like peptide-1 (GLP-1) may affect autonomic nervous system activity, HR and BP, and thus potentially alter cardiovascular outcomes. In the present issue of Diabetologia [27], Berkelaar et al examined the effects of high levels of insulin on cardiac vagal control in a large series of healthy volunteers with BMIs ranging from 18 to $36 \mathrm{~kg} / \mathrm{m}^{2}$. They used exogenous insulin infusion (euglycaemic-hyperinsulinaemic clamp) and stimulation of endogenous insulin production by different combinations of bolus injections and continued infusion of glucose and other secretagogues (GLP-1 and arginine) to increase levels of insulin up to a mean maximal level of $4,775 \mathrm{pmol} / 1$. At every time point of the experimental protocol, insulin levels were directly associated with HR and inversely related to indices of vagal control. However, after adjusting for age, BMI and insulin sensitivity, the associations with HR remained partially intact, while those with vagal control disappeared. This suggests that BMI and insulin sensitivity, not insulin level, are the main drivers of cardiac vagal control and vagal changes during acute pharmacologically induced hyperinsulinaemia, which is consistent with the well established defect in vagal tone in overweight individuals summarised above.

During the euglycaemic-hyperinsulinaemic clamp, HR and cardiac vagal activity (root mean square of successive differences in interbeat intervals [rMSSD IBI], HF, and peakvalley respiratory sinus arrhythmia, the latter surprisingly low at baseline) did not change significantly [27]. Previous studies have shown a marked increase, a slight increase or no increase in HR during euglycaemic clamps in healthy individuals [28, 29]. Consistent with previous reports [28, 29], HR elevation resulted from vagal depression, but it was also, and probably mostly, produced by cardiac sympathetic activation. Sympathetic activity has been assessed in previous clamp studies by measurement of a variety of variables. These reported that insulin increased MSNA [28, 30], plasma catecholamines [31, $32]$, and in some studies $[29,33]$ the LF/HF ratio, which 
indicates relative sympathetic predominance. In fact, insulin seems to produce a regionally non-uniform increase in sympathetic activity. Insulin has been observed to increase lumbar but not renal sympathetic nerve activity in animals [34], and to increase sympathetic activity to muscle but not to skin in humans [35]. The sympatho-excitatory effects of insulin result at least in part from a central neural action and possibly from baroreflex activation secondary to peripheral vasodilation induced by insulin [36]. Moreover, the absence of BP changes during hyperinsulinaemia may result from the opposing pressor (mediated by sympathetic activation) and depressor actions (vasodilation) of insulin in the skeletal vasculature.

During the euglycaemic-hyperinsulinaemic clamp the shift in cardiac autonomic nervous system activity towards sympathetic predominance (estimated by the increase in the LF/HF ratio) has been shown to be lower in obese than in lean individuals [33] and depressed in insulin-resistant patients [37]. It is increased in the offspring of insulin-resistant type 2 diabetic patients and absent in the offspring of insulin-deficient type 2 diabetic probands [38]. This suggests that chronic marked hyperinsulinaemia may prevent further enhancement of cardiac sympathetic tone during an acute rise in insulin. A similar trend towards a limited increase in sympathetic activity in obese and type 2 diabetic patients has been reported during other tests, including deep breathing, exercise and oral glucose challenge [12, 39, 40], suggesting a reduction in sympathetic reserve when sympathetic activity is relatively high at baseline. A blunted sympathetic response may result from impaired insulin transport across the blood-brain barrier, which has been shown in experimentally induced insulin resistance in dogs [41], and from lower cerebrospinal fluid insulin levels, as reported in obese insulin-resistant humans [42]. In line with this, brain insulin resistance coexists with peripheral insulin resistance $[43,44]$.

\section{Effects of GLP-1 on vagosympathetic activity}

GLP-1 may also induce changes in haemodynamic variables and modulate autonomic activity. Using a telemetry system, Griffioen et al [45] showed that in mice both acute and chronic central administration of exendin-4, a long-lasting GLP-1 receptor agonist, increased HR and reduced the HF and LF powers of HR variability. Both excitatory glutamatergic and inhibitory glycinergic neurotransmission to preganglionic parasympathetic neurons was diminished, indicating that GLP-1 receptor stimulation may induce changes in HR and HR variability by inhibiting neurotransmission to cardiac vagal neurons. GLP-1, administered peripherally or centrally, has also been shown to increase sympathetic activity in rats [46].
In a small sample of healthy individuals, GLP-1 infusion produced modest but not statistically significant increases in HR (by an average of $3 \mathrm{bpm}$ ) and BP and a statistically significant increase in MSNA [47]. However, there were no major modifications in plasma catecholamines or in cardiovagal or cardiosympathetic activity as assessed by spectral analysis of HR variability. In several trials, GLP-1 analogues have been shown to increase the pulse rate of diabetic and obese patients by around $3 \mathrm{bpm}[48,49]$, indicating that the HR increase persists with long-term treatment, and have been demonstrated to produce a statistically significant decrease in systolic BP, which seems to occur before weight loss $[48,50]$. Berkelaar et al [27] investigated GLP-1 infusion in healthy individuals during hyperglycaemia and reported a significant increase in HR of the same magnitude as the aforementioned trials ( $3 \mathrm{bpm}$ ). There was a slight, statistically non-significant decrease in measures of cardiac vagal control compared with those determined before any manipulation of insulin levels. This does not exclude the possibility that GLP-1-induced vagal depression could have been greater in the absence of prior hyperglycaemia and hyperinsulinaemia. Cardiac sympathetic control was not assessed with the power of the LF band or by measuring catecholamine changes, but the data suggested that sympathetic activity was enhanced since HR and systolic BP increased significantly and the double product of HR by systolic BP, a sympathetic activation index, increased accordingly. The increase in HR may be due to the huge increase in endogeneous insulin levels (50-fold increase from baseline to the end of GLP-1 infusion) and insulin-mediated sympathetic activation, or to a proper sympathoexcitatory effect of GLP-1 or a direct effect on the myocardium, where GLP-1 receptors have been shown to be present [51]. C-peptide may also play a role in the regulation of the autonomic nervous system [52], but it is not known whether the action of GLP-1 could be partly mediated by the increase in C-peptide secretion.

More data are needed on the mechanisms through which GLP-1 may affect HR and BP, acutely or during long-term treatment, and further studies on the effects of GLP-1 on haemodynamics and autonomic activity in diabetic and obese patients are required, since this may influence cardiovascular prognosis.

Insulin and GLP-1 share common effects that can contribute to an increase in HR, including vagal depression, sympathetic activation and, possibly, enhancement of the baroreflex secondary to endothelium-induced vasodilation. Both hormones may potentially affect BP in different ways depending on the presence of hypertension, cardiac autonomic impairment and endothelium function. Furthermore, the autonomic nervous system might also affect the haemodynamic response to GLP-1 through its regulatory effect on insulin secretion. 
Duality of interest The authors declare that there is no duality of interest associated with this manuscript.

Contribution statement All authors were responsible for the conception and design of the manuscript, drafting the article and revising it critically for important intellectual content. All authors approved the version to be published.

\section{References}

1. Carnethon MR, Yan L, Greenland P et al (2008) Resting heart rate in middle age and diabetes development in older age. Diabetes Care 31:335-339

2. Stein PK, Barzilay JI, Domitrovich PP et al (2007) The relationship of heart rate and heart rate variability to non-diabetic fasting glucose levels and the metabolic syndrome: the Cardiovascular Health Study. Diabet Med 24:855-863

3. Palatini P (1999) Dynamic monitoring of blood pressure and assessment of antihypertensive drugs. Cardiologia 44(Supp1 1):1007-1010 [article in Italian]

4. Spallone V, Ziegler D, Freeman R et al (2011) Cardiovascular autonomic neuropathy in diabetes: clinical impact, assessment, diagnosis, and management. Diabetes Metab Res Rev 27:639-653

5. The Diabetes Control and Complications trial Research Group (1998) The effect of intensive diabetes therapy on measures of autonomic nervous system function in the Diabetes Control and Complications Trial (DCCT). Diabetologia 41:416-423

6. Gaede P, Lund-Andersen H, Parving H-H, Pedersen O (2008) Effect of a multifactorial intervention on mortality in type 2 diabetes. N Engl J Med 358:580-591

7. Valensi P, Thi BN, Lormeau B, Paries J, Attali JR (1995) Cardiac autonomic function in obese patients. Int $\mathrm{J}$ Obes Relat Metab Disord 19:113-118

8. Laitinen T, Lindstrom J, Eriksson J et al (2011) Cardiovascular autonomic dysfunction is associated with central obesity in persons with impaired glucose tolerance. Diabet Med 28:699-704

9. Valensi P, Extramiana F, Lange C et al (2011) Influence of blood glucose on heart rate and cardiac autonomic function. The DESIR study. Diabet Med 28:440-449

10. Valensi P, Paries J, Attali JR (2003) Cardiac autonomic neuropathy in diabetic patients: influence of diabetes duration, obesity, and microangiopathic complications - the French multicenter study. Metabolism 52:815-820

11. Liao D, Sloan RP, Cascio WE et al (1998) Multiple metabolic syndrome is associated with lower heart rate variability. The Atherosclerosis Risk in Communities Study. Diabetes Care 21:2116-2122

12. Straznicky NE, Grima MT, Sari CI et al (2012) Neuroadrenergic dysfunction along the diabetes continuum: a comparative study in obese metabolic syndrome subjects. Diabetes 61:2506-2516

13. Maser RE, Lenhard MJ (2007) An overview of the effect of weight loss on cardiovascular autonomic function. Curr Diabetes Rev 3:204-211

14. Toyry JP, Niskanen LK, Mantysaari MJ et al (1997) Do high proinsulin and C-peptide levels play a role in autonomic nervous dysfunction? Power spectral analysis in patients with non-insulin-dependent diabetes and nondiabetic subjects. Circulation 96:1185-1191

15. Carnethon MR, Prineas RJ, Temprosa M, Zhang Z-M, Uwaifo G, Molitch ME (2006) The association among autonomic nervous system function, incident diabetes, and intervention arm in the Diabetes Prevention Program. Diabetes Care 29:914-919

16. de Jonge L, Moreira EA, Martin CK, Ravussin E (2010) Impact of 6-month caloric restriction on autonomic nervous system activity in healthy, overweight, individuals. Obesity (Silver Spring) 18:414 416
17. Straznicky NE, Eikelis N, Nestel PJ et al (2012) Baseline sympathetic nervous system activity predicts dietary weight loss in obese metabolic syndrome subjects. J Clin Endocrinol Metab 97:605-613

18. Bobbioni-Harsch E, Sztajzel J, Barthassat V et al (2005) The effect of insulin on cardiac autonomic balance predicts weight reduction after gastric bypass. Diabetologia 48:1258-1263

19. Valensi P, Paries J, Lormeau B, Attia S, Attali J-R (2005) Influence of nutrients on cardiac autonomic function in nondiabetic overweight subjects. Metabolism 54:1290-1296

20. Lindmark S, Lonn L, Wiklund U, Tufvesson M, Olsson T, Eriksson JW (2005) Dysregulation of the autonomic nervous system can be a link between visceral adiposity and insulin resistance. Obes Res 13:717-728

21. Pop-Busui R, Evans GW, Gerstein HC et al (2010) Effects of cardiac autonomic dysfunction on mortality risk in the Action to Control Cardiovascular Risk in Diabetes (ACCORD) trial. Diabetes Care 33:1578-1584

22. Valensi P, Doare L, Perret G, Germack R, Paries J, Mesangeau D (2003) Cardiovascular vagosympathetic activity in rats with ventromedial hypothalamic obesity. Obes Res 11:54-64

23. Cosson E, Herisse M, Laude D et al (2007) Aortic stiffness and pulse pressure amplification in Wistar-Kyoto and spontaneously hypertensive rats. Am J Physiol Heart Circ Physiol 292:2506-2512

24. Ayad F, Belhadj M, Paries J, Attali JR, Valensi P (2010) Association between cardiac autonomic neuropathy and hypertension and its potential influence on diabetic complications. Diabet Med 27:804-811

25. Grassi G, Seravalle G, Dell'Oro R, Turri C, Bolla GB, Mancia G (2000) Adrenergic and reflex abnormalities in obesity-related hypertension. Hypertension 36:538-542

26. Grassi G, Dell'Oro R, Quarti-Trevano F et al (2005) Neuroadrenergic and reflex abnormalities in patients with metabolic syndrome. Diabetologia 48:1359-1365

27. Berkelaar M, Eekhoff EMW, Simonis-Bik AMC et al (2013) Effects of induced hyperinsulinaemia with and without hyperglycaemia on measures of cardiac vagal control. Diabetologia. doi:10.1007/s00125-013-2848-6

28. van de Borne P, Hausberg M, Hoffman RP, Mark AL, Anderson EA (1999) Hyperinsulinemia produces cardiac vagal withdrawal and nonuniform sympathetic activation in normal subjects. Am J Physiol 276:178-183

29. Bellavere F, Cacciatori V, Moghetti P et al (1996) Acute effect of insulin on autonomic regulation of the cardiovascular system: a study by heart rate spectral analysis. Diabet Med 13:709-714

30. Vollenweider L, Tappy L, Owlya R, Jequier E, Nicod P, Scherrer U (1995) Insulin-induced sympathetic activation and vasodilation in skeletal muscle. Effects of insulin resistance in lean subjects. Diabetes 44:641-645

31. Rowe JW, Young JB, Minaker KL, Stevens AL, Pallotta J, Landsberg L (1981) Effect of insulin and glucose infusions on sympathetic nervous system activity in normal man. Diabetes $30: 219-225$

32. Tack CJ, Lenders JW, Willemsen JJ et al (1998) Insulin stimulates epinephrine release under euglycemic conditions in humans. Metabolism 47:243-249

33. Paolisso G, Manzella D, Tagliamonte MR, Rizzo MR, Gambardella A, Varricchio M (1999) Effects of different insulin infusion rates on heart rate variability in lean and obese subjects. Metabolism 48:755-762

34. Morgan DA, Balon TW, Ginsberg BH, Mark AL (1993) Nonuniform regional sympathetic nerve responses to hyperinsulinemia in rats. Am J Physiol 264:423-427

35. Berne C, Fagius J, Pollare T, Hjemdahl P (1992) The sympathetic response to euglycaemic hyperinsulinaemia. Evidence from microelectrode nerve recordings in healthy subjects. Diabetologia $35: 873-879$

36. Scherrer U, Sartori C (1997) Insulin as a vascular and sympathoexcitatory hormone: implications for blood pressure 
regulation, insulin sensitivity, and cardiovascular morbidity. Circulation 96:4104-4113

37. Paolisso G, Manzella D, Rizzo MR et al (2000) Effects of insulin on the cardiac autonomic nervous system in insulin-resistant states. Clin Sci (Lond) 98:129-136

38. Laitinen T, Vauhkonen IK, Niskanen LK et al (1999) Power spectral analysis of heart rate variability during hyperinsulinemia in nondiabetic offspring of type 2 diabetic patients: evidence for possible early autonomic dysfunction in insulin-resistant subjects. Diabetes 48:1295-1299

39. Valensi P, Smagghue O, Paries J, Velayoudon P, Lormeau B, Attali JR (2000) Impairment of skin vasoconstrictive response to sympathetic activation in obese patients: influence of rheological disorders. Metabolism 49:600-606

40. Tentolouris N, Tsigos C, Perea D et al (2003) Differential effects of high-fat and high-carbohydrate isoenergetic meals on cardiac autonomic nervous system activity in lean and obese women. Metabolism 52:1426-1432

41. Kaiyala KJ, Prigeon RL, Kahn SE, Woods SC, Schwartz MW (2000) Obesity induced by a high-fat diet is associated with reduced brain insulin transport in dogs. Diabetes 49:1525-1533

42. Kern W, Benedict C, Schultes B et al (2006) Low cerebrospinal fluid insulin levels in obese humans. Diabetologia 49:2790-2792

43. Anthony K, Reed LJ, Dunn JT et al (2006) Attenuation of insulinevoked responses in brain networks controlling appetite and reward in insulin resistance: the cerebral basis for impaired control of food intake in metabolic syndrome? Diabetes 55:2986-2992

44. Tschritter O, Preissl H, Hennige AM et al (2006) The cerebrocortical response to hyperinsulinemia is reduced in overweight humans: a magnetoencephalographic study. Proc Natl Acad Sci U S A 103:12103-12108

45. Griffioen KJ, Wan R, Okun E et al (2011) GLP-1 receptor stimulation depresses heart rate variability and inhibits neurotransmission to cardiac vagal neurons. Cardiovasc Res 89:72-78

46. Yamamoto H, Lee CE, Marcus JN et al (2002) Glucagon-like peptide-1 receptor stimulation increases blood pressure and heart rate and activates autonomic regulatory neurons. J Clin Invest 110:43-52

47. Bharucha AE, Charkoudian N, Andrews CN et al (2008) Effects of glucagon-like peptide-1, yohimbine, and nitrergic modulation on sympathetic and parasympathetic activity in humans. Am J Physiol Regul Integr Comp Physiol 295:874-880

48. Russell-Jones D, Vaag A, Schmitz O et al (2009) Liraglutide vs insulin glargine and placebo in combination with metformin and sulfonylurea therapy in type 2 diabetes mellitus (LEAD-5 met+SU): a randomised controlled trial. Diabetologia 52:20462055

49. Astrup A, Carraro R, Finer N et al (2012) Safety, tolerability and sustained weight loss over 2 years with the once-daily human GLP-1 analog, liraglutide. Int J Obes (Lond) 36:843-854

50. Nauck M, Frid A, Hermansen K et al (2009) Efficacy and safety comparison of liraglutide, glimepiride, and placebo, all in combination with metformin, in type 2 diabetes: the LEAD (Liraglutide Effect and Action in Diabetes)-2 study. Diabetes Care 32:84-90

51. Wei Y, Mojsov S (1996) Distribution of GLP-1 and PACAP receptors in human tissues. Acta Physiol Scand 157:355-357

52. Wahren J (2004) C-peptide: new findings and therapeutic implications in diabetes. Clin Physiol Funct Imaging 24:180-189 